\title{
Indicadores de Desempenho como Direcionadores de Valor
}

\author{
Eduardo Sérgio Ulrich Pace \\ Leonardo Fernando Cruz Basso \\ Marcos Alessandro da Silva
}

\section{Resumo}

Este trabalho evidencia quais as medidas estratégicas mais usadas junto à comunidade dos analistas financeiros, além das medidas tradicionais, tendo como base a sua capacidade de prever valor e a sua facilidade de obtenção. Os resultados revelam a existência de importantes hiatos de comunicação entre a empresa e os analistas e eles não reconhecem como as medidas contidas nos instrumentos de planejamento estratégico voltadas para recursos humanos, satisfação do consumidor e qualidade dos produtos, podem agregar valor. Medidas tradicionais e financeiras têm uso predominante por sua facilidade de obtenção. A capacidade de prever valor será encontrada nas medidas de governança e de eficiência de processos, aí predominando medidas não-financeiras; mas o seu acesso é limitado pelos custos de obtenção e pela falta de políticas de divulgação.

Palavras-chaves: criação de valor; mensuração de desempenho; direcionadores de valor.

\section{Abstract}

This work determines the extend to which analysts use strategic performance measures in addition to traditional financial measures and in what intensity their use in a developing economy is influenced not only by the capacity to predict the value contained in information divulged by companies, but also by its ease of acquisition. The result of the survey was similar to the values obtained in the United States, referring to the predominance of traditional financial indicators, observing a trend for dependence on these indicators alone to change. The results obtained in the analyst's view of strategic measures recommended by the balanced scorecard related to product quality, customer satisfaction and human resource management were not as high as expected. On the other hand corporate governance and process efficiency demonstrated a superior performance, which was not the case of social responsibility categories, which were among those with the worst performance. A communication gap between companies and investors was found and should be overcome by the dialogue between investment analysts and companies with the disclosure of non-financial measures.

Key words: value creation; performance measures; value drivers. 


\section{INTRODUÇÃO}

As limitações decorrentes da administração apenas com base em medidas financeiras são conhecidas há décadas e as tentativas de se incorporar medidas não-financeiras constituem coleções de medidas, servindo mais como relações de controle para acompanhamento e melhoria do que sistemas inteligíveis de medidas interligadas, sem qualquer relação com a estratégia (Kaplan e Norton, 2001).

O crescimento da importância dos ativos intangíveis, como fator decisivo na obtenção da vantagem competitiva, caracteriza o final do século XX, levando as organizações a buscar como melhor medi-los e apresentá-los aos administradores e aos investidores. O seu valor depende do ambiente organizacional e da estratégia e não pode ser isolado dos processos que os transformam em resultados financeiros, dado o fato de que balanços são lineares e cumulativos, o que não ocorre com os ativos intangíveis. Estes podem criar valor para a organização, mas dificilmente podem ter valor de mercado claramente identificável.

Eccles e Mavrinac (1995) confirmam, em relação a esses problemas que, nas empresas voltadas para o lucro, os analistas financeiros reconhecem a importância da informação não-financeira para suas avaliações, servindo ainda como indicador estratégico de tendência, útil para o sucesso financeiro na gestão empresarial de longo prazo. Contudo Dempsey et al. (1997) apontam que a facilidade de acesso a indicadores não financeiros é limitada, principalmente em se tratando de medidas relativas à qualidade do produto e à satisfação do consumidor. Apesar de utilizadas internamente nas empresas na aplicação de instrumentos de planejamento e de controle estratégico, quando abertas ao público elas se apresentam limitadas, dada sua extrema diversidade e ausência de padrão único para divulgação. As medidas financeiras, por sua vez, têm larga vantagem quanto à facilidade de acesso, dadas as regras de divulgação em vigor.

Essa busca de informações pelas organizações para seu uso na tomada de decisões de investimento irá até o ponto em que seus custos marginais de aquisição igualarem seus benefícios, o que também deverá reger o seu comportamento na divulgação das informações (Dempsey et al., 1997).

No presente trabalho formula-se o seguinte problema de pesquisa: 
Numa economia emergente a capacidade de prever valor e a facilidade de obtenção das medidas estratégicas de desempenho têm permitido utilizálas como indicadores de tendência nas projeções dos analistas financeiros, podendo influenciar o comportamento dos gestores das empresas?

Buscou-se determinar com que amplitude os analistas fazem uso de diferentes medidas estratégicas de desempenho ou têm interesse em utilizá-las, além das tradicionais medidas financeiras e mensurar como a capacidade de prever valor e a facilidade de obtenção explicam o uso das diferentes medidas de desempenho. A identificação da existência de hiatos críticos de informação entre a utilidade da previsão e a facilidade de obtenção de determinadas medidas mostra como os gestores atendem às demandas dos analistas.

O levantamento da literatura concernente à mensuração do desempenho destaca que, para se conseguir um ambiente eficaz de gestão, faz-se necessário incorporar um sistema de medidas que assegure o alinhamento das atividades com o objetivo maior da organização.

Os indivíduos, por sua vez, devem perceber e influenciar as ligações existentes entre suas atividades, além de atuar sobre o valor da corporação. A qualidade da sua tomada de decisão em relação a cada atividade e a sua execução também serão influenciadas pela existência de um sistema apropriado de medidas.

\section{Referencial Teórico}

\section{Sistemas de Mensuração de Desempenho}

A análise e a mensuração de desempenho podem ser definidas literalmente como o processo de se quantificar uma ação, no qual mensuração é o processo de quantificação e a ação é aquilo que provoca o desempenho, afirma Neely (1995).

Um bom administrador controla o desempenho dos sistemas sob sua responsabilidade com a ajuda de medidas de desempenho. Como esses sistemas se desenvolveram e como evoluíram pode ser mais bem compreendido por meio do conhecimento das forças que os moldaram, afirma Kaplan (1983), sendo raro encontrar-se um único fator como responsável por determinada ação. Normalmente, ocorre uma combinação de fatores e forças que levam a organização a dirigir-se para determinada direção. 
Uma síntese produzida por Waggoner (1999) identifica essas forças em quatro categorias como possíveis formadoras e direcionadoras da evolução e das mudanças incorridas pelos sistemas de mensuração de desempenho organizacional. São elas:

. influências internas, ou seja, relações de poder e coalizões de interesses dominantes;

. influências externas, ou seja, a legislação e a volatilidade dos mercados;

. aspectos do processo, ou seja, formas de implementação e de gestão dos processos políticos; e

- aspectos da mudança, ou seja, graus de apoio dos níveis superiores e riscos de ganho ou de perda decorrentes da mudança.

Mesmo que se entenda mensuração como processo de quantificação, seus efeitos estimulam a ação e a estratégia só existirá e será praticada se for possível identificar um padrão consistente de decisões e ações na organização (Mintzberg, 1978).

A literatura acadêmica destaca exaustivamente o papel e a importância das medidas de desempenho, ao focar pessoas e recursos na direção desejada. Kaplan e Norton (1993) afirmam que o desenvolvimento e a aplicação de um conjunto equilibrado de medidas propiciam o melhor uso das medidas existentes e que, ao ampliarem os sistemas de mensuração, provocam a melhoria do desempenho da organização.

A plena utilidade daqueles sistemas se dá quando forem capazes de se ajustar às influências externas ou mudanças ambientais, levando parte dos estudos contemporâneos, que buscam explicar a mudança organizacional, a serem realizados tendo em vista aspectos ambientais como a volatilidade e o posicionamento competitivo (Barnett e Carrol, 1995).

Se por um lado as medidas de desempenho constituem a variável crítica para a afirmação do sucesso pessoal, da equipe ou de grupos, por outro lado elas não podem deixar de estar em permanente renovação na busca de ganhos ampliados, afirmam Teng, Grover e Fiedler (1996). Entre os obstáculos à transformação que ocorrem com a implantação de novas iniciativas e estratégias, está a intensidade da resistência oposta pelos membros de uma organização, que está relacionada com sua percepção dos ganhos e perdas decorrentes da mudança e como a cultura corporativa irá provocar uma resposta. Uma cultura que desencoraja a exposição ao risco e à inovação é obstáculo essencial à mudança que visa à 
implantação de um sistema de mensuração de desempenho. Kaplan e Norton (2001b), ao analisarem cinco princípios que orientam uma organização focada na estratégia, apontam que, para se alinhar uma organização a uma estratégia, é preciso enfrentar functional silos, que constituem obstáculos à implementação estratégica, dados os conjuntos de conhecimento funcional, a linguagem e cultura próprias.

\section{Características das Medidas Estratégicas de Desempenho}

\section{Medidas Financeiras}

São conhecidas e exaustivamente lembradas as limitações referentes aos sistemas tradicionais de mensuração financeira como forma de avaliar o sucesso ou o fracasso dos administradores. Maskell (apud Manoochehri, 1999), destaca algumas destas limitações.

. Ausência de relevância. É comum as demonstrações contábeis não estarem diretamente ligadas à estratégia produtiva, que busca desempenho na satisfação do cliente, na qualidade, na flexibilidade e na inovação. Estas metas estratégicas, bem como os controles operacionais de índices de produtividade, ciclos de produção e taxas de rejeição não são monitorados pelos relatórios tradicionais.

. Distorções nos custos. A apropriação dos custos com base no custeio por atividade busca resolver as distorções provocadas pelo custeio direto.

- Falta de flexibilidade. As características de objetividade e consistência, inerentes à contabilidade, tornam seus demonstrativos menos flexíveis para atender às variadas necessidades das diferentes plantas, produtos, processos, departamentos e equipes.

. Freqüência e oportunidade dos relatórios. Níveis de excelência na área produtiva exigem respostas e retornos rápidos da linha de produção, sendo importante lembrar que a contabilidade não trata os intangíveis, o que pode ocasionar distorções nos resultados e restrição à busca da excelência produtiva.

- Obstáculos ao progresso na direção da excelência de processo. Excessivo foco nos custos pode restringir melhorias nos projetos. Assim é o caso do custo de um investimento que propicia maior flexibilidade, mas de difícil justificativa, pois a flexibilidade não pode ser medida, nem relatada, pois é um intangível.

Os sistemas tradicionais de mensuração de desempenho comprometem a ca- 
pacidade das projeções de desempenho, pois a base de dados contábeis orienta a coleta e a análise de dados financeiros históricos, denominados indicadores de ocorrências (lagging indicators). Ao buscarem identificar lucratividade e participação de mercado, satisfação de clientes, retenção de clientes, habilidades dos funcionários, prazos e incertezas dos fluxos de caixa futuros, não podem ser vistos como indicadores de tendência ou vetores de desempenho (leading indicators), pois indicam o desempenho após a ocorrência dos fatos, ou seja, são indicadores de ocorrência da criação de valor e não estão focados na capacidade de agregar valor futuro. Por exemplo, qual o papel dos indicadores financeiros numa análise de valor econômico, quando esta propõe ajustes às regras contábeis geralmente aceitas e ao cálculo do custo do capital nas taxas de retorno do investimento?

\section{Medidas Não-Financeiras}

Existem inúmeras formas de se desenvolver boas medidas de desempenho, mas nem sempre é fácil consegui-las. As medidas financeiras se apresentam muito padronizadas entre empresas e setores econômicos e encontram-se subordinadas às normas ditadas pelas autoridades e fundamentadas em práticas contábeis centenárias e de grande aceitação. Uma análise com base no EVA®, por exemplo, não constituiu boa previsão para o desempenho futuro (Young, 2001). Para se obterem volumes crescentes de EVA ${ }^{\circledR}$ será preciso conhecer os indicadores de tendência (leading indicators), capazes de sinalizar a criação de valor ou sua destruição antes que os resultados surjam.

Medidas proativas capazes de prevenir, antecipar e influenciar resultados futuros constituem indicadores de tendência. Em contraste, medidas reativas relatam o ocorrido, mostrando os resultados do desempenho do sistema, não sendo úteis nas decisões relativas a futuros desenvolvimentos e ações.

Dessa forma, a utilidade dos indicadores de ocorrência para os administradores desejosos de aperfeiçoar seus processos em ambientes competitivos e em condições críticas será cada vez mais limitada (Kaplan e Norton, 1992; Ittner, 1998; Low, 1999).

Esta não é uma sugestão de que devam ser eliminados os sistemas financeiros tradicionais; contudo medidas agregadas, como, por exemplo, ROI, ROE e lucro operacional, não são mais capazes de captar a complexidade e os valores contidos no ambiente empresarial. Este ambiente está orientado por processos, em que predominam aspectos relativos à identificação de oportunidades, velocidade de aprendizado, inovação, duração dos ciclos, qualidade, flexibilidade, confiabilidade e capacidade de resposta, que precisam ser medidos. Assim, tal qual é feito com 
os indicadores de desempenho macroeconômicos, medidas de desempenho estratégico, identificadas na cadeia de valor empresarial, devem preceder e auxiliar a mensuração dos resultados financeiros. Elas exigem sistemas de mensuração ampliados, para incorporar medidas confiáveis de previsão do desempenho empresarial, capazes de mostrar, não só as implicações dessas estratégias de longo prazo, mas também se algo está fora de controle, antes que um prejuízo maior ocorra (Neely, 1995; Dempsey et al., 1997).

Measelle (apud Dempsey et al., 1997) destaca a necessidade de informações que atendam aos investidores na busca do correto valor de longo prazo das empresas de capital aberto, cada vez mais coincidente com aquelas utilizadas internamente pelos administradores.

Visando a atender essas necessidades dos mercados, diferentes trabalhos foram desenvolvidos na busca:

. da identificação de medidas não-financeiras, úteis para o melhor conhecimento das operações;

. do desenvolvimento de sistemas estratégicos de mensuração mais abrangentes, compreendendo medidas financeiras e não-financeiras; e

- de sistemas de informação de desempenho capazes de se alinhar com as metas estratégicas e medir seu progresso em relação a elas (Eccles, 1991; Eccles et al., 1992; Kaplan e Norton, 1992; Nanni et al., 1992; Low, 1998).

As pesquisas relativas à importância e aceitação das medidas não-financeiras têm evoluído por diferentes caminhos, seja como indicadores de tendência que propiciam informações sobre o desempenho futuro, em que a prática tem demonstrado grande dificuldade para relacionar estas medidas com desempenhos contábeis, seja no valor de suas ações no mercado (Brancato, 1995; Ittner e Larcker, 1996, 1998), seja no uso de medidas não-financeiras em planos de remuneração (Ittner, Larcker e Rajan, 1997).

O seu baixo uso pelos administradores é devido à má compreensão da importância das conseqüências que sua atuação pode ter sobre aquelas medidas. Esses administradores também estariam confusos quanto às formas de reconciliação entre as medidas financeiras e não-financeiras, ressaltando ainda mais a necessidade de treinamento.

Eccles et al. (2001), ao mostrarem os benefícios decorrentes de uma maior abertura de informações e quanto relevante é o custo de sua obtenção, discutem que a construção de um sistema estratégico de mensuração é mais do que a 
simples coleta de dados não financeiros, devendo apresentar equilíbrio e integração, com um desenho que permita destacar fatores críticos de sucesso. Ele permitirá aos administradores ver onde o valor está sendo criado, onde são necessários investimentos e melhorias e onde as estratégias da empresa estão sendo bem sucedidas, afirmam Vitale, Mavrinac e Hauser (1994), ao sugerirem uma metodologia de implementação.

Lynch e Cross (1995) afirmam que, para se desenvolver um sistema adequado de mensuração, deve-se mapear os processos, identificando as seqüências de atividades e seus principais agentes. O próximo passo será a determinação das áreas, onde os indicadores de desempenho serão críticos para o sucesso do processo (value drivers). Os administradores poderão usar medidas amplas de desempenho, visando a verificar se a empresa estará fazendo progresso na sua eficiência operacional; mas estas, é preciso lembrar, são apenas medidas de ocorrência. Nestes procedimentos os administradores estarão focados nas ações que hoje podem produzir melhor desempenho financeiro futuro. Cada unidade irá então definir objetivos operacionais, considerando três elementos críticos: a satisfação do cliente, a flexibilidade dos processos produtivos e a produtividade, ou seja, como recursos financeiros e humanos serão administrados para atender aos elementos anteriores.

\section{A Combinação de Medidas Financeiras e Não-Financeiras}

Os criadores do balanced scorecard, Kaplan e Norton (1992), ao proporem a fusão de medidas financeiras e não-financeiras, perceberam que medidas criam foco para o futuro; as medidas escolhidas pelos administradores comunicam importantes mensagens a todos os níveis e pessoas da organização (Kaplan e Norton, 2001a). Assim, buscam uma abordagem ampliada da mensuração do desempenho e afirmam que sua aplicação propicia uma ferramenta capaz de traduzir a visão e a estratégia da organização, comunicando os objetivos estratégicos e motivando o desempenho em face das metas estabelecidas. Trata-se de um instrumento capaz de descrever estratégias que criam valor, quando ligam ativos tangíveis com intangíveis. Contudo reconhecem que, "apesar de suas qualidades para fins de uso interno e divulgação externa, ele não está adaptado para o melhor entendimento da comunidade de investidores e analistas, que está pouco interessada em fazer uma troca por uma análise e por um relato mais estratégico e menos financeiro" (Kaplan e Norton, 1993, p. 141). 


\section{Atributos das Medidas Estratégicas de Desempenho}

\section{A Freqüência de Uso das Informações Não-Financeiras}

Estudos sobre a complementação entre as medidas financeiras e não-financeiras de Amir e Lev (1996) e sobre a avaliação do potencial de valorização das ações, contidos nas informações não-financeiras, destacam a existência de um incremento de valor da empresa, verificável por meio do preço de suas ações no mercado, como decorrência principalmente do maior uso das informações.

A este respeito, Dempsey et al. (1997) destacam a freqüência de uso (frequency of use) das informações não-financeiras como capazes de superar a contribuição dos indicadores financeiros tradicionais. Uma análise da freqüência de uso deve buscar compreender como se dá a troca de informações entre os participantes do mercado de capitais. Nesse sentido, dois aspectos pesquisados por Eccles e Mavrinac (1995), quando verificam como administradores, investidores e analistas de mercado percebem a necessidade de alterar as normas de divulgação para o mercado de capitais e como as empresas se comunicam com ele, referem-se à transparência das informações e à qualidade das comunicações para o mercado. Aí, apontam como fundamental sua capacidade de se comunicar interna e externamente e reconhecem a importância e as dificuldades dessa comunicação.

Nessa direção, Ittner, Larcker e Rajan (1998), De Haas (2000) e Olve (apud Norreklit, 2000) ampliam essas dificuldades, ao detalharem as limitações apresentadas na comunicação interna no caso do BSC, que pretende ser capaz de ampliar o entendimento das metas internas e das ligações existentes entre elas. A forma hierárquica de sua implementação, aliada à falta de vínculo entre gerentes e os demais funcionários, transforma o BSC em instrumento com estratégia apenas vertical, com baixo comprometimento funcional no sentido horizontal entre as áreas, afirma De Haas (2000), sugerindo a aplicação de um método de discussão até que se logre o consenso na busca de uma coerência entre as medidas (De Haas, 1999; Norreklit, 2000; Young, 2001).

A necessidade da combinação coerente e do alinhamento dos recursos existentes é reconhecida por Kaplan e Norton (2001a) como a melhor forma a ser usada pela organização para alcançar um desempenho excepcional, capitalizando recursos e ativos, ambos tangíveis e intangíveis, já nela existentes. Lembram que o BSC não constitui um projeto de mensuração, mas de mudança (Kaplan e Norton, 2001a). 


\section{A Capacidade de Prever Valor}

Eccles (1995) identifica um consenso quanto às imperfeições de funcionamento dos mercados de capitais e destaca que não há interesse dos seus pesquisados no aumento dos regulamentos voltados para a maior divulgação de dados financeiros. Assim o incremento no processo de abertura pode dar-se por meio de maior transparência e melhor comunicação, com estímulo a uma estratégia de informações corporativas, ampliação das funções do responsável pelas relações com o mercado ou divulgação voluntária de informações não-financeiras.

A incapacidade de os administradores atuarem de forma proativa com seus interlocutores do mercado e, como conseqüência, com os investidores, gera nestes uma dificuldade no entendimento correto de suas estratégias, de suas medidas de desempenho e, em última análise, fica reduzida a sua capacidade de previsão de eventos futuros (predictive value).

Pesquisa recente elaborada pelo Ernst \& Young Center for Business Innovation (Low, 1998), constatou importantes alterações na participação das informações não-financeiras nas mensurações de desempenho:

. a ampliação significativa na influência das informações não-financeiras utilizadas pelos analistas em suas avaliações e recomendações de compra e venda;

. o maior interesse apresentado pelos analistas em fatores relacionados com a execução da estratégia, com a credibilidade da administração, com a inovação e o posicionamento mercadológico, que ficaram muito acima dos aspectos relativos às reclamações de clientes, programas de treinamento funcional e políticas socioambientais;

. a variação, segundo a indústria, da importância atribuída às medidas não-financeiras, não está ligada a uma estratégia em particular ou a determinado tipo de investidor;

. os analistas que se apóiam mais intensamente nas informações não-financeiras são aqueles que produzem as projeções mais corretas; se a empresa tiver forte desempenho nos aspectos não financeiros e souber comunicá-los, terá mais facilidade para captar recursos de terceiros;

. um terço da informação utilizada pelos investidores institucionais serviu de justificativa para seus novos investimentos;

. a existência de uma relação entre as mudanças naquelas informações e as variações no valor das ações e, portanto, em seu custo de capital. 
O estudo evidencia que os investidores buscam conhecer, de forma mais profunda, o modelo de negócio, com visão dos principais indicadores de desempenho, que estão atentos aos aspectos não financeiros, usando-os para direcionar sua decisão de investir e que não só as medidas não-financeiras afetam o valor das ações, como é possível mensurar sua magnitude de variação. Ele mostra como dados não financeiros influem sobre o valor da empresa. Contudo é fundamental que ela desenvolva a função de comunicação, para se alinhar com as necessidades dos investidores de obter informações não-financeiras com medidas de desempenho mais uniformes e precisas e menos subjetivas.

É oportuno mencionar, como complemento às medidas não-financeiras pesquisadas por Dempsey (1997), que os analistas, atuando como facilitadores, tem feito uso de outras variáveis para gerar informações aos investidores (Low, 1999):

- a habilidade da empresa em executar a estratégia proposta, entendida como a capacidade dos administradores de tomarem medidas fortes e de aproveitarem oportunidades rapidamente;

- a capacidade de alcançar as metas estabelecidas no prazo dentro dos valores orçados;

. a maior credibilidade da administração;

. a avaliação da qualidade da estratégia;

- a capacidade de inovar;

- a capacidade de atrair e reter funcionários capazes;

. o posicionamento de mercado;

. a experiência dos administradores;

. os processos de remuneração profissional;

- a qualidade dos principais processos produtivos e a liderança em pesquisa.

Ao se examinar a relação da empresa com o mercado de investimentos e o papel dos analistas financeiros, quanto à sua capacidade de previsão e de influência, deve-se observar que analistas financeiros têm função vital nos mercados de investimentos e financeiro (Cote, 2000), pois sua perspectiva independente monitora e interpreta as relações de agência entre os administradores e os acionistas, reduzindo os custos de agência; sua reputação de independência e de 
confiabilidade na identificação do valor da empresa possibilita que essa atividade prospere.

\section{A Facilidade de Obtenção de Informações e o Hiato de Comunicação}

O funcionamento do mercado é afetado pela existência de várias falhas de comunicação (communications gap). A existência de tais falhas entre gestores, investidores e analistas, conforme consenso entre os pesquisados por Eccles (1995), afeta seus mecanismos de alocação de recursos, podendo produzir ênfase maior nas análises de curto prazo, desestimulando os administradores a realizar investimentos de longo prazo. Os administradores podem, alternativamente, responder de diferentes formas: aperfeiçoando a comunicação das estratégias e dos desempenhos esperados ou limitando as comunicações com os analistas, distanciando-se do mercado.

Em trabalho sobre divulgação voluntária de dados, constatou-se que os administradores variam suas estratégias de divulgação, apresentando dados complementares, segundo o tipo de notícias sobre os resultados projetados: notícias boas ou más afetam diferentemente o conteúdo das projeções. Dado que más notícias são prontamente aceitas como verídicas, há uma preocupação em explicar suas causas, buscando-as externamente à empresa, como falhas nos suprimentos, alterações nas condições da mão-de-obra etc. Quando se trata de boas notícias, dado que os investidores são mais céticos em relação a elas, os administradores tendem a ser mais específicos em suas afirmações, apresentando dados mais facilmente verificáveis e buscando discutir aspectos que afetam o setor, a indústria e a economia e as suas perspectivas futuras. Portanto essas informações mais detalhadas, que acompanham as previsões, são necessárias para enfatizar a eficácia das políticas dos administradores.

Low (1999) reformula a constatação coletada por Eccles e Mavrinac (1995), para quem cabe às medidas financeiras dos lucros, das taxas de crescimento e do fluxo de caixa serem aquelas mais requisitadas pelos analistas e investidores e as mais divulgadas pelos administradores das empresas, enquanto as medidas relativas aos funcionários são consideradas de menor importância.

Outra constatação surpreendente, afirmam Eccles e Mavrinac (1995), foi o baixo número de empresas com uma política formal de divulgação, sendo visto o responsável por essa tarefa como fator facilitador ou impeditivo do acesso a mais informação. Em se tratando da disponibilidade dos dados e da facilidade de obtêlos (ease of acquisition), cabe observar qual o tipo de mídia e qual a freqüência das comunicações utilizadas (Eccles e Mavrinac, 1995). 
Para que a informação tenha conteúdo, deve existir diálogo, conforme verificou Eccles (1991), pois o que os analistas desejam é a oportunidade de trabalhar com os executivos para produzirem suas projeções e validarem seus modelos, tendo reduzido interesse nas projeções das empresas. Assim, fazendo uso de maior transparência, os administradores terão maior credibilidade, constituindose no melhor instrumento para dar visibilidade de longo prazo à empresa, podendo ser útil quando os resultados atuais não forem bons.

\section{Resultados}

\section{Amostra}

A amostra dos analistas financeiros foi obtida junto aos afiliados à Associação Brasileira de Mercado de Capitais - ABAMEC SP. Os profissionais selecionados com 95,5\% de confiança e constituindo 58\% dos respondentes concentramse no cargo de analistas de pesquisa (research), com um erro de 13\%; $20 \%$ pertencem a corretoras de valores, com o mesmo grau de confiança, com um erro de $11 \%$. Ainda, com o mesmo grau de confiança, sua área de atuação está $64 \%$ concentrada em títulos de renda variável, mercado doméstico, com um erro de $13 \%$, voltados para empresas não pertencentes ao setor financeiro, a publicações financeiras ou ligadas ao governo. De um total de 554 nomes obteve-se um retorno de 83 respondentes, sendo aproveitados 56 ou 10,1\% . Foi disponibilizado um site eletrônico em cooperação com a ABAMEC SP, com uma mensagem em que se convocavam os associados a participar da pesquisa.

\section{Pesquisa}

O Quadro 1 apresenta as medidas organizadas sob nove categorias:
(A) Financeiras
(B) Qualidade de Produto
(C) Satisfação do Cliente
(D) Eficiência de Processos
(E) Inovação de Produto e Processo

(F) Ambiente Competitivo

(G) Qualidade e Independência de Gestão

(H) Administração de Recursos Humanos

(I) Responsabilidade Social 


\section{Quadro 1: Medidas Pesquisadas}

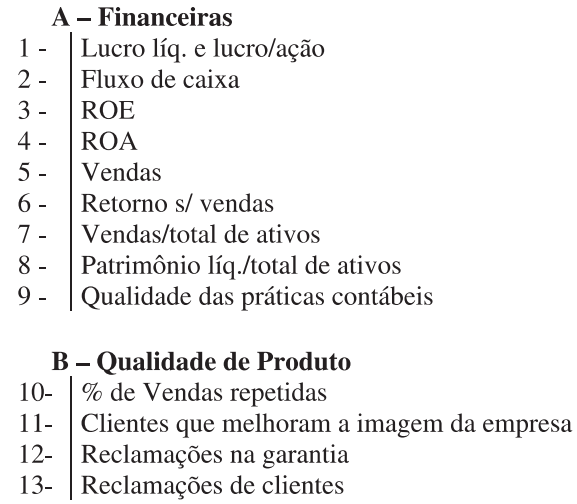

\section{C - Satisfação do Cliente}

14- Pesquisa de mercado

15- Entregas pontuais

16- Tempo de resposta dos serviços

17- \% de clientes fidelizados

18- VPL da carteira de clientes

19- \% de clientes contatados que concretizam operações

20-Disputas judiciais com clientes

\section{D - Eficiência de Processo}

21- Taxa de quantidade de defeitos

22- Tempo de desenvolvimento de produtos

23- Tempo de ciclo de fabricação

24- Tempo entre pedido e entrega

25- Capacidade de customização

26- Custos operacionais/ empregado

27- Vendas/funcionário

28- CMV/estoques

29- Contas a receber/vendas

30- Investimento de capital

31- Idade da planta e equipamentos

32- Uso da capacidade instalada

\section{E - Inovação de Produto/Processo}

33- Gastos com P\&D

34- \% de produtos patenteados

35- Número de novas patentes

36- Número de novos produtos

37- \% de vendas de novos produtos

\section{F - Ambiente Competitivo}

38- Participação de mercado

39- Percepção da marca

40- Concorrência potencial

41- Proteção por tarifas/quotas

42- \% de vendas de produtos patenteados

43- Alianças estratégicas

44- Disputas c/ legislação antitruste

45- Diversificação geográfica

46- Diversificação de clientes

47- Diversificação de produtos

\section{G - Qualidade/Independência de Gestão}

48- Continuidade de gestão

49- Experiência/reputação dos administradores

50- Envolvimento do cons. de administração

51- Independência do cons. de administração

52- Disputas com acionistas

53- Diluição de controle

54- Comportamento ético dos administradores

55- Valor oferecido ao investidor

H- Administração de Recursos Humanos

56- Igualdade de oportunidades no emprego

57- Participação funcional

58- Participação nos lucros

59- Plano de opção de compra de ações

60- \% candidatos a vagas em concorrentes e recrutados pela empresa

61- Desenvolvimento de empregos/empregados

62- \% de novos funcionários

63- Política de Benefícios

\section{I - Responsabilidade Social}

64- Proteção às minorias

65- Desempenho em ações ambientais

66- Envolvimento c/ a comunidade

67- Disputas judiciais

Para cada medida foi solicitado aos analistas que indicassem a existência das seguintes características, fazendo uso de uma escala Likert de cinco pontos ( 5 = alto, 1 = baixo):

. Freqüência de Uso (FU): qual a freqüência de uso daquela medida no processo de avaliação do desempenho de longo prazo da empresa? 
- Capacidade de Prever Valor (PV): qual a capacidade observada de prever valor contido em cada medida?

. Facilidade de Obtenção (FO): qual é a facilidade observada de obtenção de informações em cada medida?

A relação de causa e efeito entre aquelas variáveis foi expressa por:

$$
\mathbf{F U}=\mathbf{f}(+\mathbf{P V},+\mathbf{F O})
$$

\section{Análise de Resultados}

Buscando identificar a existência de diferenças significativas entre os valores médios obtidos para cada medida em relação às características mencionadas, foi desenvolvida uma análise de clusters.

Na Tabela 1 as medidas de Freqüência de Uso foram ordenadas de sempre (5) a nunca (1), utilizadas e distribuídas entre cinco clusters com base nos valores médios, divididos de modo a acompanhar a escala de cinco pontos, utilizada no questionário de respostas. A natureza da análise baseada em clusters não permite a definição de um número correto de agrupamentos. Os dados foram forçados a ter conformidade com o número especificado a priori pelos pesquisadores. Desse modo, não há teste relevante para se apurar sua significância estatística.

As medidas mais freqüentemente utilizadas foram: Vendas (4,6), Fluxo de Caixa $(4,5)$ no primeiro cluster. No topo do segundo cluster foram encontradas as medidas Participação de Mercado (4,02), Lucro Líquido e Lucro por Ação (4,0), Investimento de Capital (3,93), Disputas com Acionistas (3,93), Qualidade das Práticas Contábeis $(3,9)$. No último cluster foram encontradas Entregas Pontuais $(1,95)$, Reclamações na Garantia $(1,87)$, Igualdade de Oportunidades no Emprego $(1,84)$ e \% de Candidatos a Vagas em Concorrentes Recrutados pela Empresa $(1,67)$. As duas categorias de uso mais freqüente são Financeiras, bem como as 5 das 10 primeiras listadas. Se também os aspectos financeiros contidos na medida de Investimento de Capital $(3,93)$ forem aqui considerados, haverá predominância de medidas financeiras. Contudo, ampliando-se a análise para a inclusão das 21 medidas que compõem os dois primeiros clusters, 15 medidas são não-financeiras. Por outro lado, apenas 6 das primeiras 21 podem ser consideradas medidas não tradicionais e não utilizadas numa análise tradicional. Patrimônio Líquido/Ativos (3,1) foi a medida financeira mais mal classificada. 


\section{Tabela 1: Freqüência de Uso - Análise de Cluster para os Valores Médios}

\begin{tabular}{|c|c|c|c|c|c|}
\hline Medida & $\mathbf{C t}$ & $\mathbf{M}$ & Medida & $\mathbf{C t}$ & $\mathbf{M}$ \\
\hline Vendas & $\mathrm{A}$ & 4,60 & Participação nos Lucros & $\mathrm{H}$ & 2,98 \\
\hline Fluxo de Caixa & A & 4,50 & Tempo do Ciclo de Fabricação & D & 2,91 \\
\hline Part. De Mercado & $\mathrm{F}$ & 4,02 & Gastos c/ P\&D & $\mathrm{E}$ & 2,85 \\
\hline Lucro Líq. e Lucro/Ação & A & 4,00 & Opção de Compra de Ações & $\mathrm{H}$ & 2,82 \\
\hline Investimento de Capital & $\mathrm{D}$ & 3,93 & $\%$ de Vendas de Novos Produtos & $\mathrm{E}$ & 2,65 \\
\hline Disputas c/ Acionistas & G & 3,93 & VPL da Carteira de Clientes & $\mathrm{C}$ & 2,56 \\
\hline Qualidade das Práticas Contábeis & A & 3,90 & Desempenho em Ações Ambientais & I & 2,55 \\
\hline Uso da Capacidade Instalada & $\mathrm{D}$ & 3,89 & Disputas Judiciais c/ Clientes & $\mathrm{C}$ & 2,53 \\
\hline Concorrência Potencial & $\mathrm{F}$ & 3,85 & Tempo entre Pedido/Entrega & $\mathrm{D}$ & 2,51 \\
\hline ROE & A & 3,70 & Número de Novos Produtos & $\mathrm{E}$ & 2,49 \\
\hline Diluição do Controle & G & 3,69 & Política de Benefícios & $\mathrm{H}$ & 2,47 \\
\hline Diversificação de Clientes & $\mathrm{F}$ & 3,69 & Clientes que Melhoram a Imagem da & & \\
\hline Diversificação de Produtos & $\mathrm{F}$ & 3,64 & Empresa & $\mathrm{B}$ & 2,42 \\
\hline Alianças Estratégicas & $\mathrm{F}$ & 3,62 & Pesquisa de Mercado & $\mathrm{C}$ & 2,42 \\
\hline Continuidade de Gestão & G & 3,62 & $\%$ de Clientes Fidelizados & $\mathrm{C}$ & 2,40 \\
\hline Diversificação Geográfica & $\mathrm{F}$ & 3,60 & $\%$ Vendas de Produtos Patenteados & $\mathrm{F}$ & 2,35 \\
\hline $\begin{array}{l}\text { Comportamento ético do } \\
\text { administrador }\end{array}$ & G & 3,58 & $\%$ de Vendas Repetidas & $\mathrm{B}$ & 2,25 \\
\hline Idade da Planta, dos Equipamentos & $\mathrm{D}$ & 3,53 & Tempo de Desenvolvimento de Produtos & $\mathrm{D}$ & 2,24 \\
\hline $\begin{array}{l}\text { Experiência/reputação do } \\
\text { administrador }\end{array}$ & G & 3,51 & Capacidade de Customização & $\mathrm{D}$ & 2,16 \\
\hline Retorno s/ Vendas & A & 3,50 & Participação Funcional & $\mathrm{H}$ & 2,16 \\
\hline Valor oferecido aos Investidor & G & 3,49 & $\begin{array}{l}\% \text { de Clientes Contatados que Concretizam } \\
\text { Operações }\end{array}$ & $\mathrm{C}$ & 2,15 \\
\hline Contas a Receber/Vendas & $\mathrm{D}$ & 3,35 & Taxa de Quantidade de Defeitos & $\mathrm{D}$ & 2,13 \\
\hline Proteção por Tarifas/Quotas & $\mathrm{F}$ & 3,31 & Envolvimento c/ a Comunidade & $\mathrm{I}$ & 2,11 \\
\hline CMV/Estoques & $\mathrm{D}$ & 3,24 & Tempo de Resposta dos Serviços & $\mathrm{C}$ & 2,11 \\
\hline Vendas/Funcionários & $\mathrm{D}$ & 3,22 & Número de Novas Patentes & $\mathrm{E}$ & 2,11 \\
\hline $\begin{array}{lll}\text { Disputas com a Legislação } \\
\text { Antitruste }\end{array}$ & $\mathrm{F}$ & 3,22 & $\%$ de Novos Funcionários & $\mathrm{H}$ & 2,07 \\
\hline ROA & A & 3,20 & Proteção às Minorias & I & 2,05 \\
\hline Custos Operacionais/Funcionário & $\mathrm{D}$ & 3,18 & $\%$ de Produtos Patenteados & $\mathrm{E}$ & 2,02 \\
\hline $\begin{array}{l}\text { Independência do Cons. de } \\
\text { Administr. }\end{array}$ & G & 3,15 & Reclamações de Clientes & $\mathrm{B}$ & 2,00 \\
\hline Disputas com Judiciais & I & 3,15 & Desenvolv. de Empregos/Empregados & $\mathrm{H}$ & 2,00 \\
\hline Vendas /Total Ativos & A & 3,10 & Entregas Pontuais & $\mathrm{C}$ & 1,95 \\
\hline Patrimônio Líq. / Total Ativos & A & 3,10 & Reclamações na Garantia & $\mathrm{C}$ & 1,87 \\
\hline Percepção da Marca & $\mathrm{F}$ & 3,05 & Igualdade de Oportunidades no Emprego & $\mathrm{H}$ & 1,84 \\
\hline $\begin{array}{l}\text { Envolvimento do Cons. de } \\
\text { Administração }\end{array}$ & G & 2,98 & $\begin{array}{l}\% \text { de Candidatos a Vagas em Concorrentes } \\
\text { Recrutados pela Empresa }\end{array}$ & $\mathrm{H}$ & 1,67 \\
\hline
\end{tabular}

\author{
$\mathrm{Ct}=$ Categoria \\ $\mathrm{A}=$ Financeiras \\ $\mathrm{B}=$ Qualidade de Produtos \\ $\mathrm{C}=$ Satisfação de Clientes \\ $\mathrm{D}=$ Eficiência de Processos \\ $\mathrm{E}=$ Inovação de Produtos e Processos
}

$$
\begin{aligned}
& M=\text { Média } \\
& F=\text { Ambiente Competitivo } \\
& \mathrm{G}=\text { Qualidade/Independência de Gestão } \\
& \mathrm{H}=\text { Administração de Recursos Humanos } \\
& \mathrm{I}=\text { Responsabilidade Social }
\end{aligned}
$$

Estes resultados da classificação e a pequena dispersão observada entre os valores médios sugerem uso intenso das medidas destacadas. Fica evidenciada também a tendência a favor do uso de medidas não-financeiras. Cabe notar que uma medida ligada às políticas contidas nos conceitos de governança corporativa, 
Disputas com Acionistas (3,93), foi classificada em sexto lugar, seguida por Qualidade das Práticas Contábeis $(3,90)$ que, apesar de pertencer à categoria Financeiras (A), contém aspectos de relações com o mercado e de governança. Devese observar ainda que a medida Valor para o Investidor $(3,49)$ se encontra no final do segundo cluster, acima da mediana $(2,98)$. Uma conclusão inesperada refere-se às medidas não tradicionais, ligadas aos recentes desenvolvimentos na área de planejamento estratégico, como, por exemplo, se recomenda no balanced scorecard, que parecem não estar sendo utilizadas.

Na Tabela 2 as medidas referentes à Capacidade de Prever Valor variam de muito alta (5) a nenhuma (1).

\section{Tabela 2: Capacidade de Prever Valor - Análise de Cluster para os Valores Médios}

\begin{tabular}{l}
$\quad$ Medida \\
Clientes que Melhoram a \\
Imagem da Empresa \\
Diluição do Controle \\
Independência do Cons. de Adm. \\
Vendas \\
Fluxo de Caixa \\
\hline Retorno s/ Vendas \\
Uso da Capacidade Instalada \\
Participação de Mercado \\
Lucro Líq. E Lucro/Ação \\
Diversificação de Clientes \\
Contas a Receber/Vendas \\
Investimento de Capital \\
Concorrência Potencial \\
Diversificação Geográfica \\
Idade da Planta e Equipamentos \\
ROE \\
Diversificação de Produtos \\
Vendas/Total de Ativos \\
Patrimônio Líq. / Total de Ativos \\
Qualidade das Práticas Contábeis \\
Vendas por Funcionários \\
Custos Oper. / Funcionários \\
Proteção por Tarifas / Quotas \\
Disputas com Acionistas \\
ROA \\
Continuidade de Gestão \\
CMV / Estoques \\
Experiência/Reputação dos Adm. \\
Valor oferecido a o Investidor \\
Percepção da Marca \\
Alianças Estratégicas \\
Comportamento ético dos \\
administradores \\
Tempo de Fabricação \\
VPL da Carteira de Clientes \\
\end{tabular}

Ct M

B 4,00

G $\quad 4,00$

G $\quad 4,00$

A 3,90

A 3,70

A 3,40

D 3,35

F 3,31

A 3,30

F 3,29

D 3,29

D 3,27

F 3,27

F 3,24

D 3,22

A 3,20

F 3,18

A 3,10

A 3,10

A 3,10

D 3,09

D 3,05

F 3,04

G 3,00

A 3,00

G 2,98

D 2,93

G 2,89

G 2,82

F 2,80

F 2,76

G 2,75

D 2,73

C 2,71
Medida

Disputas c/ legislação antitruste

Participação nos Lucros $\quad \mathrm{H} \quad 2,62$

Envolvimento Cons. Administ.

Tempo entre Pedido e Entrega

Gastos com P\&D

$\%$ Venda de produtos patenteados

$\%$ Clientes Fidelizados

$\%$ Vendas de Novos Produtos

Opção de Compra de Ações

Ações Ambientais

$\%$ Vendas Repetidas

Número de Novos Produtos

Pesquisa de Mercado

$\%$ de clientes contatados que

concretizaram operações

Capacidade de Customização

Reclamações de Clientes

Tempo de Resposta de Serviços

Taxa de Quantidade de Defeitos

Tempo de Desenvolvimento Prod.

Disputas Judiciais

Proteção às Minorias

Desenv. de empreg. e empregados

$\%$ de Entregas Pontuais

$\%$ de Produtos Patenteados

Número de Novas Patentes

Disputas Judiciais c/ Clientes

Envolvimento com Comunidade

Política de Benefícios

Reclamações na Garantia

Participação Funcional

Igualdade de Oportunidade no Emprego

$\%$ de Candidatos a vagas em concorrentes e

recrutados

$\%$ de Novos Funcionários

$\mathrm{H} \quad 1,85$

$\mathrm{H} \quad 1,75$ 
Aqui, o padrão é alterado em relação à Freqüência de Uso quando, das 10 primeiras medidas apontadas como possuidoras da Capacidade de Prever Valor, apenas 4 pertencem à categoria Financeiras (A). Porém esta categoria está totalmente contida nos dois primeiros clusters e sua dispersão não é acentuada. As 3 primeiras medidas são não-tradicionais e pertencem à categoria Qualidade/ Independência de Gestão $(G)$ com Diluição do Controle $(4,0)$ e Independência do Conselho de Administração $(4,0)$ e à categoria Qualidade do Produto (B) com Clientes que Melhoram a Imagem da Empresa (4,0). Esta medida também se refere às relações com clientes, pois atribui elevada importância à qualidade. Esta, porém, será a única vez em que a categoria Qualidade de Produto (B) irá possuir destaque para os analistas. As outras duas medidas reafirmam a ótica atual do mercado de capitais brasileiro, ao valorizar o impacto das recentes políticas de governança corporativa, implementadas pela Bolsa de Valores de São Paulo (BOVESPA) na gestão, nos resultados futuros das empresas e na atitude dos investidores. Como afirmam Steinberg e Bromilow (2000), o sucesso dessas políticas depende fundamentalmente da qualidade dos sistemas de mensuração de desempenho existentes.

As demais medidas referentes à Qualidade do Produto (B) e à Satisfação do Cliente (C) não estão entre as mais utilizadas e não são percebidas como capazes de possuir capacidade de prever valor, não estando presentes nos dois primeiros clusters de ambas as características, exceto pela medida acima mencionada e a medida VPL da Carteira de Clientes (C) $(2,56)$. Isto contraria a constatação de Larcker (apud Eccles, 2001), que indica a satisfação do cliente como direcionador de medidas de desempenho financeiro futuro. É importante observar que a categoria Ambiente Competitivo (categoria F) classificou 9 medidas entre as primeiras 35, sendo 6 entre as de maior freqüência de uso e uma categoria de medidas tradicionais, Eficiência de Processos (categoria D) está representada com 8 entre 33 medidas contidas no segundo cluster, sendo que 3 delas aparecem no topo por sua freqüência de uso e ela constitui uma das vertentes do balanced scorecard. Este destaque já não existe para as medidas referentes à Administração de Recursos Humanos (categoria H), que ocupam 5 das 10 últimas posições quanto à capacidade de prever valor. Cabe destacar que a medida de Valor Oferecido ao Investidor $(2,82)$ aparece no segundo cluster acima da mediana (2,71). Resumindo, os resultados validam a tendência mundial de mudança na prioridade dos analistas na direção da incorporação dos ativos intangíveis (Kaplan e Norton, 2001), mostrando a relevância dos direcionadores de valor da inovação e do desenvolvimento tecnológico. Por outro lado, de forma preocupante, não reconhecem nos funcionários as sempre requeridas competências, habilidade e capacidade de implementação das estratégias (Kaplan e Norton, 2001). 
$\mathrm{O}$ acesso às diferentes medidas de desempenho pela comunidade dos analistas é apresentado na Tabela 3, Facilidade de Obtenção, na qual elas variam de disponível (5) a não disponível (1).

\section{Tabela 3: Facilidade de Obtenção Análise de Clusters para os Valores Médios}

\begin{tabular}{|c|c|c|c|c|c|}
\hline Medida & $\mathbf{C t}$ & $\mathbf{M}$ & Medida & $\mathbf{C t}$ & $\mathbf{M}$ \\
\hline Vendas & $\mathrm{C}$ & 4,30 & Gastos com P\&D & $\mathrm{E}$ & 2,36 \\
\hline Lucro Líquido e Lucro / Ação & A & 4,10 & Valor Oferecido ao Investidor & $\mathrm{G}$ & 2,36 \\
\hline Patrimônio Líq. / Total de Ativos & A & 3,90 & Comportamento ético dos administr. & G & 2,36 \\
\hline Retorno sem Vendas & A & 3,80 & VPL da Carteira de Clientes & $\mathrm{C}$ & 2,31 \\
\hline Vendas / Total de Ativos & A & 3,70 & Tempo entre Pedido e Entrega & $\mathrm{D}$ & 2,25 \\
\hline ROE & A & 3,60 & $\%$ de Vendas de Prod. Patenteados & $\mathrm{F}$ & 2,24 \\
\hline Contas a Receber / Vendas & $\mathrm{D}$ & 3,45 & Clientes que melhoraram a & & \\
\hline Investimento de Capital & $\mathrm{D}$ & 3,44 & Imagem da empresa & $\mathrm{B}$ & 2,24 \\
\hline ROA & A & 3,40 & $\%$ de Vendas de Novos Produtos & $\mathrm{E}$ & 2,20 \\
\hline Fluxo de Caixa & A & 3,30 & Número de Novos Produtos & $\mathrm{E}$ & 2,16 \\
\hline Qualidade das Práticas Contábeis & A & 3,30 & Desempenho em Ações Ambientais & I & 2,16 \\
\hline Diversificação Geográfica & $\mathrm{F}$ & 3,27 & Envolvimento com a Comunidade & $\mathrm{I}$ & 2,13 \\
\hline Participação de Mercado & $\mathrm{F}$ & 3,25 & $\%$ de Clientes Fidelizados & $\mathrm{C}$ & 2,11 \\
\hline Vendas / Funcionário & $\mathrm{D}$ & 3,25 & Disputas Judiciais & I & 2,04 \\
\hline CMV / Estoques & $\mathrm{D}$ & 3,22 & $\%$ de Vendas Repetidas & B & 2,04 \\
\hline Uso da Capacidade Instalada & $\mathrm{D}$ & 3,18 & Reclamações de Clientes & $\mathrm{B}$ & 2,00 \\
\hline Diversificação de Produtos & $\mathrm{F}$ & 3,18 & Pesquisa de Mercado & $\mathrm{C}$ & 2,00 \\
\hline Diversificação de Clientes & $\mathrm{F}$ & 3,11 & Número de Novas Patentes & $\mathrm{E}$ & 1,98 \\
\hline Proteção por Tarifas / Quotas & $\mathrm{F}$ & 3,05 & Capacidade de Customização & $\mathrm{D}$ & 1,93 \\
\hline Idade da Planta e Equipamentos & $\mathrm{D}$ & 3,04 & Política de Benefícios & $\mathrm{H}$ & 1,89 \\
\hline Alianças Estratégicas & $\mathrm{F}$ & 3,00 & Proteção às Minorias & $\mathrm{I}$ & 1,89 \\
\hline Custos Operacionais/Funcionário & $\mathrm{D}$ & 2,87 & Participação Funcional & $\mathrm{H}$ & 1,84 \\
\hline Diluição do Controle & G & 2,85 & Tempo de Desenv. de Produtos & $\mathrm{D}$ & 1,84 \\
\hline Concorrência Potencial & $\mathrm{F}$ & 2,84 & $\%$ de Clientes Contatados com & & \\
\hline Continuidade de Gestão & G & 2,80 & Operações Realizadas & $\mathrm{C}$ & 1,84 \\
\hline Disputas c/ Legislação Antitruste & $\mathrm{F}$ & 2,78 & Entregas Pontuais & $\mathrm{C}$ & 1,84 \\
\hline Disputas com Acionistas & G & 2,76 & Disputas Judiciais com Clientes & $\mathrm{C}$ & 1,82 \\
\hline$\%$ de Clientes Contatados que & & & $\%$ Produtos Patenteados & $\mathrm{E}$ & 1,82 \\
\hline Realizam Operações & $\mathrm{C}$ & 2,76 & Reclamações na Garantia & $\mathrm{B}$ & 1,73 \\
\hline Participação nos Lucros & $\mathrm{H}$ & 2,67 & $\%$ de Novos Funcionários & $\mathrm{H}$ & 1,71 \\
\hline Independência do Cons. de Adm. & $\mathrm{G}$ & 2,47 & Taxa de Quantidade de Defeitos & $\mathrm{D}$ & 1,69 \\
\hline Plano Opção de Compra de Ações & $\mathrm{H}$ & 2,42 & Desenv. de Empreg/Empregados & $\mathrm{H}$ & 1,60 \\
\hline Tempo de Ciclo Fabricação & $\mathrm{D}$ & 2,42 & Igualdade de Oportunidades & $\mathrm{H}$ & 1,60 \\
\hline Envolvimento do Conselho & & & $\%$ Candidatos a Vagas em & $\mathrm{H}$ & 1,55 \\
\hline Administrativo & G & 2,38 & Recrutados Empresa & & \\
\hline Percepção da Marca & $\mathrm{F}$ & 2,37 & & & \\
\hline
\end{tabular}

A categoria Financeiras (A) concentra, como esperado, a maior facilidade de acesso à informação. As medidas de Vendas (4,3) e Lucro Líquido/Lucro por Ação $(4,1)$ compõem o primeiro cluster, sendo que todas as medidas financeiras estão contidas nos dois primeiros clusters, o que é explicado pelo formalismo e uniformidade praticados nas informações financeiras, permitindo sua pronta disponibilização.

O quinto cluster contém medidas tidas como de mais difícil obtenção, predominando a categoria Administração de Recursos Humanos com 4 das 6 medidas 
observadas, o que pode ser explicado pelos seus elevados níveis de intangibilidade. As medidas mais mal classificadas foram: Desenvolvimento de Empregos/Empregados (1,60), Igualdade de Oportunidades no Emprego (1,60) e \% de Candidatos a Vagas em Concorrentes Recrutados pela Empresa $(1,55)$.

No segundo cluster, das 19 medidas, 7 são Financeiras (A); 6 pertencem à Eficiência de Processos (D) e sua facilidade de obtenção explica sua freqüência de uso acima da mediana e o mesmo ocorre com as 6 medidas de Ambiente Competitivo (F).

Novamente, as categorias referentes à Qualidade de Produtos (B) e Satisfação de Clientes (C) concentraram-se abaixo da mediana (2,37), no quarto cluster.

Na Tabela 4 estão classificadas as nove categorias das medidas de desempenho, segundo a Freqüência de Uso, a Capacidade de Prever Valor e a Facilidade de Obtenção. Apesar da cautela necessária ao se analisar agregados de medidas que podem ter alguma ambigüidade na sua categorização, vale destacar: as categorias Financeiras (A) e Qualidade/Independência de Gestão (G) confirmam sua classificação no topo das características de Freqüência de Uso e de Capacidade de Prever Valor, cabendo à categoria Financeiras (A) ser a de mais fácil obtenção. A Administração de Recursos Humanos $(\mathrm{H})$ apresenta os níveis mais baixos em Capacidade de Prever Valor e em Facilidade de Obtenção, sendo Qualidade de Produto (B) a categoria de menor Freqüência de Uso. Novamente a Satisfação de Clientes (C) classifica-se entre as de mais baixos valores nas três características. A má classificação da Administração de Recursos Humanos (H) continua a ser surpreendente, dada a atenção ao envolvimento de pessoas e de equipes que, combinados com a mobilização funcional, constituem fatores de sucesso das organizações (Kaplan, 2001b).

\section{Tabela 4: Classificação das Categorias das Medidas de Desempenho}

\begin{tabular}{lcccccc}
\hline Categoria & $\begin{array}{c}\text { Média de } \\
\text { Freqüência } \\
\text { de uso }\end{array}$ & $\begin{array}{c}\text { Classi- } \\
\text { ficação }\end{array}$ & $\begin{array}{c}\text { Média da } \\
\text { Capacidade de } \\
\text { Prever Valor }\end{array}$ & $\begin{array}{c}\text { Classi- } \\
\text { ficação }\end{array}$ & $\begin{array}{c}\text { Média da } \\
\text { Facilidade de } \\
\text { Obtenção }\end{array}$ & $\begin{array}{c}\text { Classi- } \\
\text { ficação }\end{array}$ \\
\hline Financeiras & 3,73 & 1 & 3,31 & 1 & 3,71 & 1 \\
\hline $\begin{array}{l}\text { Qualidade/Independência } \\
\text { de Gestão }\end{array}$ & 3,50 & 2 & 3,13 & 2 & 2,59 & 4 \\
\hline Ambiente Competitivo & 3,43 & 3 & 2,99 & 3 & 2,90 & 2 \\
\hline Eficiência de Processos & 3,02 & 4 & 2,81 & 4 & 2,72 & 3 \\
\hline Responsabilidade Social & 2,46 & 5 & 2,07 & 8 & 2,06 & 6 \\
\hline Inovação Prod./Processo & 2,42 & 6 & 2,19 & 6 & 2,10 & 5 \\
\hline Satisfação do Cliente & 2,30 & 7 & 2,09 & 7 & 1,98 & 8 \\
\hline Administração RH & 2,25 & 8 & 2,04 & 9 & 1,91 & 9 \\
\hline Qualidade de Produtos & 2,12 & 9 & 2,59 & 5 & 2,01 & 7 \\
\hline
\end{tabular}




\section{Resultados Multivariados}

Uma análise de regressão foi testada para os valores médios pesquisados, buscando-se avaliar quais os efeitos marginais da informação no uso dos analistas (uma medida poderá ter um índice elevado na capacidade de prever valor, mas seu custo de obtenção pode ser muito alto, resultando em baixo uso da medida) e observar a existência de um comportamento racional dos analistas (maior uso é associado às medidas com maior capacidade de prever valor e com maior facilidade de obtenção).

$\overline{F U i}=a_{o}+a_{1} \overline{P V 1}+a 2 \overline{F O} i$

onde:

$\overline{F U i}=$ valor médio de freqüência de uso da i-ésima medida.

$\overline{P V i}=$ valor médio da capacidade de prever valor da i-ésima medida.

$\overline{F O} i=$ valor médio da facilidade de obtenção de i-ésima medida.

ao, a1, a2 = parâmetros lineares.

No Quadro 2 foi testada a sensibilidade das 67 observações dos valores médios das respostas para cada medida de desempenho, sendo que para cada unidade de variação na capacidade de prever valor a freqüência de uso se altera em 0,481; para cada unidade de variação na facilidade de obtenção a freqüência de uso se altera em 0,562, ou seja, a facilidade de obtenção de informação justifica melhor a freqüência de uso por parte dos analistas do que a capacidade de prever valor. No modelo a variação da freqüência de uso é explicada em grande parte pelas informações contidas nas duas variáveis, capacidade de prever valor e facilidade de obtenção $(\mathrm{R} 2=0,78)$.

Na análise dos resíduos, valores altamente positivos (negativos) mostram uma medida mais (menos) utilizada do que o previsto no modelo. A existência de medidas de uma categoria com tendência a ter resíduos mais elevados (positivos ou negativos), pode ser interpretada como excesso ou falta de uso daquela categoria.

No Quadro 2, considerando-se um nível alfa $=10 \%$, em excesso de I 1,29 I, foram listadas as medidas com resíduos positivos e negativos. Os resíduos estão próximos de zero; portanto o valor estimado para a freqüência de uso não está tão distante do valor observado. A categoria G Qualidade/Independência de Gestão é aquela que acumula o maior número de resíduos, 3 de um total de 5, indicando 
uso em excesso, superando as expectativas da estimativa. As medidas de Fluxo de Caixa e Valor Oferecido ao Investidor, aqui destacadas, têm seu maior uso explicado pela valorização das medidas não-tradicionais. O menor resíduo ou menor uso indica que o valor real (observado) está abaixo do estimado. Apesar de não existir clara predominância de uma categoria, percebe-se que elas estão relacionadas a aspectos mercadológicos.

\section{Quadro 2: Regressão dos Valores Médios da Freqüência de Uso em Relação aos Valores Médios Obtidos para a Capacidade de Prever Valor e a Facilidade de Obtenção}

Resultados da Regressão:

Valor do F 115,506

R2 ajustado 0,776

No. de Observações 67

\begin{tabular}{|c|c|c|c|}
\hline Variável & Coeficiente & $\mathbf{t}$ & sig \\
\hline Intercepto & 0,204 & 1,051 & 0,297 \\
\hline Capacidade de Prever Valor & 0,481 & 4,022 & 0,000 \\
\hline Facilidade de Obtenção & 0,562 & 5,358 & 0,000 \\
\hline
\end{tabular}

Resíduos Significativos:

\begin{tabular}{|l|c|c|}
\hline \multicolumn{1}{|c|}{ Medidas Utilizadas em Excesso } & Categoria & Resíduos Padronizados \\
Disputas Judiciais & $\mathrm{I}$ & 0,80385 \\
Disputas com Acionistas & $\mathrm{G}$ & 0,73188 \\
Comportamento Ético dos Administradores & $\mathrm{G}$ & 0,72603 \\
Fluxo de Caixa & $\mathrm{A}$ & 0,66170 \\
Valor Oferecido ao Investidor & $\mathrm{G}$ & 0,60326 \\
\hline
\end{tabular}

\begin{tabular}{|l}
\multicolumn{1}{|c}{ Medidas Sub Utilizadas } \\
Independência do Conselho de Administração \\
Contas a Receber / Vendas \\
Vendas / Total de Ativos \\
Patrimônio Líquido / Total de Ativos \\
Clientes que Melhoram a Imagem da Empresa \\
Participação de Mercado
\end{tabular}

Categoria
G
D
A
A
B
F

Resíduos Padronizados

$-0,36614$

$-0,37539$

$\begin{array}{ll}\text { D } & -0,37539 \\ \text { A } & -0,67450\end{array}$

Participação de Mercado

No Quadro 3, para melhor explorar o excesso de uso ou a subutilização das medidas, foi adicionada uma dummy para a categoria informação em substituição da categoria Financeira, analisando os dados somente com as oito categorias remanescentes na equação:

$F U i=a o+a 1 P V i+a 2 F O i+b j D_{j}$

onde:

$\boldsymbol{F U} \boldsymbol{i}=$ freqüência de uso da i-ésima medida.

$\boldsymbol{P V} \boldsymbol{i}$ = capacidade de prever valor da i-ésima medida. 
$\boldsymbol{F O} \boldsymbol{i}$ = facilidade de obtenção da i-ésima medida.

$\boldsymbol{D} \boldsymbol{j}$ = variável dummy com valor um se a variável estiver na categoria j ou zero em caso contrário (categoria excluída é a Financeira).

\section{Quadro 3: Regressão de Freqüência de Uso em Relação à Capacidade de Prever Valor, à Facilidade de Obtenção e à Categoria de Informação}

Resultados da Regressão:

Valor do F . 81,906

R2 Ajustado .. 0,786

\begin{tabular}{|c|c|c|c|c|}
\hline & Somatório dos Quadrados & Graus de Liberdade & \multicolumn{2}{|c|}{$\Sigma$ dos Quadrados Médios } \\
\hline Para a Regressão & 27,998 & 3 & \multicolumn{2}{|c|}{9,333} \\
\hline Para o Resíduo & 7,178 & 63 & \multicolumn{2}{|c|}{0,114} \\
\hline Total & & 66 & & \\
\hline \multicolumn{2}{|c|}{ Variável } & Coeficiente & $\mathbf{t}$ & sig \\
\hline Intercepto & & $-0,310$ & $-0,969$ & 0,336 \\
\hline Capacidade de Pre & alor & 0,412 & 3,374 & 0,001 \\
\hline Facilidade de Obt & & 0,722 & 5,546 & 0,000 \\
\hline Dummy (*) & & 0,335 & 1,993 & 0,051 \\
\hline
\end{tabular}

As variáveis independentes justificam a variável dependente por meio do modelo de regressão utilizado. Quando o modelo é utilizado para categorias não-financeiras, a Freqüência de Uso tem acréscimo de justificativa de apenas 0,335, sendo que a mudança no intercepto para - 0,310 explica a reação adversa no comportamento dos analistas, quando não há o uso das variáveis financeiras. Ao se introduzir a dummy em lugar da categoria financeira, o coeficiente da Capacidade de Prever Valor continuou quase inalterado $(0,412)$; mas aquele da Facilidade de Obtenção aumentou sensivelmente $(0,722)$, evidenciando a preferência dos analistas por medidas facilmente acessíveis (financeiras) em detrimento das não-financeiras. Estas seriam mais usadas apenas quando mais facilmente disponíveis.

Na Tabela 5 estão os resultados da análise do hiato de comunicação sob a ótica da falta de divulgação que condiciona, segundo Eccles (2001), o surgimento da ausência de informação. O hiato é definido para uma variável i, como a diferença entre sua capacidade de prever valor e sua facilidade de obtenção, ponderada pela capacidade de prever valor:

\section{GAPi $=($ PVi - FOi $)$ PVi}

O tamanho da diferença entre a utilidade da medida e sua disponibilidade externa mede a disparidade entre ambas: resultados maiores mostram maior disparidade entre a importância atribuída e a sua disponibilidade; resultados menores/negativos, menor a disparidade, ou seja, há excesso de informação. 
As três medidas cujos resultados positivos se destacam das demais são: Clientes que Melhoram a Imagem da Empresa (categoria B), que já se mostrava de difícil obtenção na Tabela 3, no quarto cluster, abaixo da mediana e no Quadro 2 encontrava-se entre as medidas com maiores resíduos negativos; Independência do Conselho de Administração (categoria G), que já surgia na Tabela 4 entre as medidas com resíduos negativos; Diluição do Controle (categoria G). Entre as vinte primeiras medidas na Tabela 5, predomina a categoria G Qualidade/Independência de Gestão, com 6 ocorrências e a Eficiência de Processos, com 4 ocorrências, o que pode ser explicado pela falta de um sistema formal de informações ao mercado e pelos custos que os analistas incorrem para consegui-las (Eccles, 2001).

\section{Tabela 5: Hiato de Comunicação das Medidas de Desempenho}

\begin{tabular}{|l|c|l|l|}
\hline \multicolumn{1}{|c|}{ Medida } & Ct & Hiato & \\
\hline $\begin{array}{l}\text { Clientes que Melhoram a imagem } \\
\text { da Empresa }\end{array}$ & $\mathrm{B}$ & 7,04 & 1 \\
\hline Independência Conselho de Adm. & $\mathrm{G}$ & 6,12 & 2 \\
\hline Diluição do Controle & $\mathrm{G}$ & 4,60 & 3 \\
\hline Fluxo de Caixa & $\mathrm{A}$ & 1,48 & 4 \\
\hline Concorrência Potencial & $\mathrm{F}$ & 1,41 & 5 \\
\hline Valor oferecido ao Investidor & $\mathrm{G}$ & 1,30 & 6 \\
\hline Percepção da Marca & $\mathrm{F}$ & 1,20 & 7 \\
\hline VPL da Carteira de Clientes & $\mathrm{C}$ & 1,08 & 8 \\
\hline Comportamento Ético Adm. & $\mathrm{G}$ & 1,07 & 9 \\
\hline Tempo de Fabricação & $\mathrm{D}$ & 0,85 & 10 \\
\hline Desenv.Empregos/Empregados & $\mathrm{H}$ & 0,80 & 11 \\
\hline Taxa de Defeitos & $\mathrm{D}$ & 0,79 & 12 \\
\hline Disputas com Acionistas & $\mathrm{G}$ & 0,72 & 13 \\
\hline \%Clientes Contatados c/ Vendas & $\mathrm{C}$ & 0,69 & 14 \\
\hline Envolvimento do Cons. Adm. & $\mathrm{G}$ & 0,63 & 15 \\
\hline \% Vendas Repetidas & $\mathrm{B}$ & 0,62 & 16 \\
\hline Tempo entre Pedido e Entrega & $\mathrm{D}$ & 0,60 & 17 \\
\hline Diversificação de Clientes & $\mathrm{F}$ & 0,59 & 18 \\
\hline \% Clientes Fidelizados & $\mathrm{C}$ & 0,59 & 19 \\
\hline Idade da Planta/Equipamentos & $\mathrm{D}$ & 0,58 & 20 \\
\hline Igualdade de Oportunidades & $\mathrm{H}$ & 0,57 & 21 \\
\hline Uso da Capacidade Instalada & $\mathrm{D}$ & 0,57 & 22 \\
\hline \% Candidatos a Vagas em & & & \\
\hline $\begin{array}{l}\text { Concorrentes Recrutados pela } \\
\text { Empresa }\end{array}$ & $\mathrm{H}$ & 0,56 & 23 \\
\hline Custo Oper. / Funcionário & $\mathrm{D}$ & 0,55 & 24 \\
\hline Continuidade de Gestão & $\mathrm{G}$ & 0,54 & 25 \\
\hline \% Vendas de Prod. Patenteados & $\mathrm{F}$ & 0,49 & 26 \\
\hline Tempo de Desenv. de Produtos & $\mathrm{D}$ & 0,48 & 27 \\
\hline Pesquisa de Mercado & $\mathrm{C}$ & 0,44 & 28 \\
\hline Reclamações na Garantia & $\mathrm{B}$ & 0,43 & 29 \\
\hline Capacidade de Customização & $\mathrm{D}$ & 0,39 & 30 \\
\hline Experiência/Reputação Admin. & $\mathrm{G}$ & 0,38 & 31 \\
\hline Tempo de resposta dos serviços & $\mathrm{C}$ & 0,36 & 32 \\
\hline Desemp. das Ações Ambientais & $\mathrm{I}$ & 0,35 & 33 \\
\hline
\end{tabular}

\begin{tabular}{|l|c|l|l|}
\hline Entregas Pontuais & $\mathrm{C}$ & 0,32 & 34 \\
\hline \% Produtos Patenteados & $\mathrm{E}$ & 0,32 & 35 \\
\hline Proteção às Minorias & $\mathrm{I}$ & 0,31 & 36 \\
\hline Disputas Judiciais com Clientes & $\mathrm{C}$ & 0,27 & 37 \\
\hline \% Vendas Novos Produtos & $\mathrm{E}$ & 0,25 & 38 \\
\hline Reclamações de Clientes & $\mathrm{B}$ & 0,23 & 39 \\
\hline Gastos com P\&D & $\mathrm{E}$ & 0,22 & 40 \\
\hline Participação de Mercado & $\mathrm{F}$ & 0,20 & 41 \\
\hline Número de Produtos Novos & $\mathrm{E}$ & 0,18 & 42 \\
\hline Participação Funcional & $\mathrm{H}$ & 0,17 & 43 \\
\hline Política de Benefícios & $\mathrm{H}$ & 0,14 & 44 \\
\hline \% Novos Funcionários & $\mathrm{H}$ & 0,07 & 45 \\
\hline Disputas Judiciais & $\mathrm{I}$ & 0,06 & 46 \\
\hline Número de Novas Patentes & $\mathrm{E}$ & 0,00 & 47 \\
\hline Diversificação de Produtos & $\mathrm{F}$ & 0,00 & 48 \\
\hline Proteção por Tarifas/Quotas & $\mathrm{F}$ & $-0,03$ & 49 \\
\hline Diversificação Geográfica & $\mathrm{F}$ & $-0,1$ & 50 \\
\hline Participação nos Lucros & $\mathrm{H}$ & $-0,13$ & 51 \\
\hline Opção de Compra de Ações & $\mathrm{H}$ & $-0,25$ & 52 \\
\hline Envolvimento c/ Comunidade & $\mathrm{I}$ & $-0,33$ & 53 \\
\hline Disputas legislação Antitruste & $\mathrm{F}$ & $-0,37$ & 54 \\
\hline Vendas por Funcionários & $\mathrm{D}$ & $-0,49$ & 55 \\
\hline Contas a receber/funcionários & $\mathrm{D}$ & $-0,53$ & 56 \\
\hline Investimento de Capital & $\mathrm{D}$ & $-0,56$ & 57 \\
\hline Qualidade das Prática Contábeis & $\mathrm{A}$ & $-0,62$ & 58 \\
\hline Alianças Estratégicas & $\mathrm{F}$ & $-0,66$ & 59 \\
\hline CMV/Estoques & $\mathrm{D}$ & $-0,85$ & 60 \\
\hline ROA & $\mathrm{A}$ & $-1,20$ & 61 \\
\hline ROE & $\mathrm{A}$ & $-1,28$ & 62 \\
\hline Retorno Sobre Vendas & $\mathrm{A}$ & $-1,36$ & 63 \\
\hline Vendas & $\mathrm{A}$ & $-1,56$ & 64 \\
\hline Vendas/Total de Ativos & $\mathrm{A}$ & $-1,86$ & 65 \\
\hline Patrimônio Líq./Total Ativos & $\mathrm{A}$ & $-2,48$ & 66 \\
\hline Lucro Líq. /Lucro Ação & $\mathrm{A}$ & $-2,64$ & 67 \\
\hline & &
\end{tabular}




\section{Conclusões}

A análise da Freqüência de Uso resulta na predominância das medidas financeiras, com pouca dispersão entre os valores médios, sugerindo uso intenso e uma análise mais voltada para o curto prazo. Fica evidenciada também a importância da tendência a favor do uso de medidas não-financeiras na busca do melhor entendimento do modelo de gestão, exigindo maior qualidade e credibilidade dos administradores, bem como sua melhor postura mercadológica. Uma conclusão aparentemente inesperada refere-se às medidas não-tradicionais ligadas aos recentes desenvolvimentos na área de planejamento estratégico, como, por exemplo, recomendado na modelagem do balanced scorecard, quando a comunidade dos analistas não é capaz de destacar a importância e a utilidade de características relativas aos recursos humanos, à satisfação do consumidor e à qualidade do produto.

O melhor entendimento da origem do comportamento acima descrito é encontrado nas características de Prever Valor e de Facilidade de Obtenção. A qualidade atribuída aos indicadores de tendência surge da análise dos clusters (agrupamentos) da capacidade de prever valor, sendo, contudo, parcialmente inibida pelos resultados relativos à disponibilidade dos dados. Aí, na Capacidade de Prever Valor está o arranjo das medidas úteis para o melhor conhecimento da operação. Medidas não-tradicionais, valorizando o Conselho de Administração independente, as formas mais democráticas de controle da sociedade, a continuidade dos gestores, bem como sua experiência e comportamento ético, estão em harmonia com as recentes medidas voltadas para a governança corporativa, atestando o entendimento de sua capacidade de influir no comportamento dos gestores, nos resultados futuros e na atitude dos investidores.

A tendência mundial de mudança na prioridade dos analistas na direção da incorporação dos ativos intangíveis é reafirmada por estes resultados, em que são utilizadas outras variáveis capazes de gerar informações aos investidores, mostrando a importância dos direcionadores de valor contidos no posicionamento de mercado e na eficiência e qualidade dos processos. Contudo os resultados tradicionais obtidos neste trabalho ainda superam os aspectos agregadores de valor contidos na busca da inovação e do desenvolvimento tecnológico. Por outro lado, de forma preocupante, dado o volume de recursos alocados e as expectativas geradas pela literatura, não são reconhecidas como relevantes as sempre requeridas competência, habilidade e capacidade de implementação estratégica dos funcionários. Cabe observar que medidas relativas ao envolvimento das empresas públicas, privadas e do terceiro setor com a comunidade e o meio ambiente ainda não têm, na ótica dos analistas, a relevância desejada pelas políticas voltadas para um desempenho socialmente responsável. A ampliação da discussão, a identificação das medidas, sua utilização e 
divulgação decorrerão da maior pressão exercida pela sociedade por meio da maior normatização e das exigências dos investidores institucionais.

A disponibilidade das informações exerce papel fundamental nas decisões dos analistas que, ao adotarem um comportamento racional, podem abandonar medidas com alta capacidade de prever valor, dado seu elevado custo de obtenção e a busca de uma análise de curto prazo decorrente da volatilidade da economia do país. A possível ausência de políticas de divulgação somente agrava este problema. Adicionalmente, deve-se observar que o formalismo e a uniformidade praticados nas informações financeiras permitem sua pronta disponibilização, enquanto medidas não-financeiras, ao padecerem da ausência daquelas duas características, levam investidores e analistas à falta do melhor entendimento de sua importância e de sua contribuição à criação de foco estratégico interna e externamente à instituição. O possível desalinhamento daí decorrente, entre as necessidades dos investidores e as práticas de gestão pode comprometer o planejamento de longo prazo. Esse acúmulo de informações apenas para uso interno é de pouca utilidade no mercado de capitais, dada a correlação existente entre melhor abertura, melhores estratégias e projeções mais ajustadas com resultados superiores no desempenho, no valor de mercado e na redução de custos.

As características dos hiatos de comunicação explicam os baixos resultados da avaliação das perspectivas contidas no balanced scorecard referentes à satisfação do cliente, à qualidade do produto e à gestão de recursos humanos.

\section{RefERÊnCIAS Bibliográficas}

AMIR, E.;

LEV, B.

Value-relevance of non financial information: the wireless communications industry.

Journal of Accounting and Economics, p. 22, 1996.

\section{BALOG, S.}

What an analyst wants from you.

Management Strategy, 1991.
BARNETT, W. P.;

CARROL, G. R.

Modeling internal organizational change. Annual Review of Sociology, p. 21, 1995.

BECKER, B.;

HUSELID, M.

High performance work systems and firm performance: a synthesis of research and managerial implications. Research in Personnel and Human Resources Management, 1998. 
BRANCATO, C. K.

New performance measures: a research report. The Conference Board, Report n. 1118-95-RR, 1995.

COTE, J.

Analyst credibility: investor's perspective. Journal of Managerial Issues, p. 12, 2000.

DE HAAS, M. et al.

Macro and micro goals setting in search of coherence. Applied Psychology, p. 49, 2000.

DEMPSEY, S. et al.

The use of strategic performance variable as leading indicators in financial analysts' forecasts. Disponível em: <http://proquest.umi.com/ pqdweb> Acesso em: 02 jun. 2001.

ECCLES, R. G. et al.

The value reporting revolution. New York: John Wiley \& Sons, 2001.

ECCLES, R. G.

The performance measurement manifesto. Harvard Business Review, Jan.-Feb. 1991.

ECCLES, R. G.;

MAVRINAC, S.

Improving the corporate disclosure process. Sloan Management Review, v. 36, 1995. Disponível em: <http:// proquest.umi.com/pqdweb> Acesso em: 02 mar. 2001.

FISHER, D.

Use of non financial performance measures. In: Readings in Management Accounting. New Jersey: Prentice-Hall, 1995.

ITTNER, C. D.;

LARCKER, D.

Total quality management and the choice of information and reward systems. Journal of Accounting Research, p. 33, 1995.

ITTNER, C. D.; LARCKER, D.;

RAJAN, M.

The choice of performance measures in annual bonus contracts. The Accounting Review, p. 72, 1997.

Innovations in performance measurement: trends and research implications. Disponível em: <http://papers.sssm.com> Acesso em: 03 out. 2000.

KAPLAN, R. S.

Measuring manufacturing performance: a new challenge for managerial accounting research. The Accounting Review, 1983.

KAPLAN, R. S.;

NORTON, D.

The balanced scorecardmeasures that drive performance. Harvard Business Review, Jan.-Feb. 1992. 
Putting the balanced scorecard to work. Harvard Business Review, Sept.-Oct. 1993.

The balanced scorecard: translating strategy into action. Harvard Business School Press, 1996.

Transforming the balanced scorecard from performance measurement to strategic management - Part I. Accounting Horizons, v. 15, n. 1, Mar. 2001a. Disponível em: $<$ http://ebsco.com> Acesso em: 05 out. 2001.

Transforming the balanced scorecard from performance measurement to strategic management - Part II. Accounting Horizons, v. 15, n. 2, June 2001b. Disponível em: $<$ http://ebsco.com> Acesso em: 05 out. 2001.

LOW, J.;

SIESFELD, $\mathrm{T}$.

Wall Street considers more than you think. Strategy \& Leadership, v. 2, 1998. Disponível em: <http:// proquest.umi.com/pqdweb> Acesso em: 11 jun. 2001.

Gauging results: what measures matter? Harvard Management Update, v. 4., 1999. Disponível em: <http://proquest.umi.com/ pqdweb> Acesso em: 11 jun. 2001.
LYNCH, R.; CROSS, K.

Measure up. Cambridge, MA: Blackwell Publishers, 1995.

\section{MANOOCHEHRI, G.}

The road to manufacturing excellence: using performance measures to become world-class. Industrial Management, 1999.

MINTZBERG, $\mathrm{H}$.

The nature of managerial work. New York: Harper \& Row, 1973.

NEELY, A.;

GREGORY, M.

Performance measurement system design. International Journal of Operations \& Producy Management, v. 15, 1995. Disponível em: <http:// ebsco.com> Acesso em: 12 jul. 2001.

NORREKLIT, $\mathrm{H}$.

The balance on the balanced scorecard: a critical analysis of some of its assumptions. Management Accounting Research, v. 11, 2000.

PERERA, S.;

HARRINSON, G.;

POOLE, M.

Customer focused manufacturing strategy and the use of operations based non financial performance measures: a research note. Accounting Organizations and Society, v. 22, 1997. 
ROGERS, E. M.

Diffusion of innovations. New York: The Free Press, 1995.

STEINBERG, R.; BROMILOW, C.

Corporate governance and the board - what works best. In: Institute of internal auditors research foundation. New York: PricewaterhouseCoopers, 2000.

TENG, J. C.;

GROVER, V.;

FIEDLER, K.

Developing strategic perspectives on business process reengineering: from process reconfiguration to organizational change. Research in Organizational Change and Development, v. 9, 1996.

TUCKMAN, B. W.

Conducting educational research. New York: Harcourt Brace, 1972.

VITALE, M.;

MAVRINAC, S.;

HAUSER, M.

New process/financial scorecard: a strategic performance measurement system. Planning Review, 1994.

WAGGONER, D. B.;

NEELY, A.;

KENNERLEY, M.

The forces that shape organizational performance measurement systems: an interdisciplinary review. International Journal of Production Economics, 1999.

WHITE, H.;

ECCLES, R.

The new Palgrave dictionary of economics. [S.l.: s.n.], 1996.

YOUNG, D. S.;

O'BYRNE, S.

EVA and value-based management. New York: McGraw-Hill, 2000.

YOUNG, S. M.; SELTO, F. H.

Explaining cross-sectional workgroup performance differences in a JIT facility. Journal of Management Accounting, 1993. 